\title{
A riqueza simbólica do candomblé nas artes visuais brasileiras: o caso de Rubem Valentim
}

\section{RESUMO}

Este escrito busca pensar sobre a riqueza simbólica e cultural que os negros escravizados trouxeram de África para o Brasil e que resiste e toma força na religião do candomblé. Uma multiplicidade de povos negros africanos foi forçada a vir para o Brasil e tais povos ainda podem ser identificados em nossa sociedade atual. Influenciando as mais diversas áreas culturais brasileiras, a população negra contribuiu de forma significativa para a constituição do que vem a ser atualmente o Brasil. Trazidos de diferentes lugares do continente africano, os negros escravizados trouxeram consigo uma forte memória histórica e cultural. Trouxeram, também, suas crenças religiosas e seus orixás. Neste texto, tomaremos como caso de estudo a arte do artista plástico baiano Rubem Valentim (Salvador, 1922 - São Paulo, 1991), importante utilizador dos signos do candomblé para compor seus trabalhos visuais de arte abstrata. Valentim criou uma verdadeira linguagem estética própria de utilização dos signos do candomblé em seus trabalhos. Esta pesquisa tem cunho analítico-qualitativo e busca suas bases em uma bibliografia nas áreas da antropologia e das artes. Os resultados deste trabalho mostram a fundamental relevância do candomblé na formação cultural brasileira e sua inserção nas mais variadas áreas de saberes e fazeres, assim como o fez nas artes plásticas e, em especial nas obras de Rubem Valentim, que foi extremamente influenciado pelo candomblé. Além disto, este texto pode auxiliar na divulgação da arte afro-brasileira abstrata, deixando conhecer não somente a arte visual do artista Rubem Valentim, mas instigando outras buscas em relação às artes e o candomblé.

PALAVRAS-CHAVE: Candomblé. Símbolos. Rubem Valentim. Artes plásticas. 


\section{INTRODUÇÃO}

Este artigo tem como objetivo principal compreender a riqueza simbólica e cultural do candomblé e compreender como tais valores influenciaram todas as áreas da vida brasileira, principalmente as artes. Nosso caso de estudo para este trabalho é a arte do baiano Rubem Valentim, artista multifacetado e um dos grandes expoentes do construtivismo brasileiro.

Nossa pesquisa para este artigo tem um caráter analítico e trabalha com dados qualitativos. Isto a partir de uma bibliografia das áreas da antropologia e das artes visuais, tentando deixar compreender a vasta possibilidade de criações artísticas a partir da multiplicidade de referências oferecidas pelo candomblé.

Neste texto começaremos mostrando um pouco sobre a riqueza simbólica do candomblé e como ela fortemente influenciou e influencia o Brasil. Mostraremos como através do tráfico de humanos, em que diversos povos negros foram escravizados saberes e fazeres africanos Depois, buscaremos explicar um pouco sobre as obras de artes de Rubem Valentim, dando um exemplo da riqueza simbólica do candomblé em um de seus trabalhos; e finalizaremos com algumas considerações sobre como este trabalho pode contribuir para a valorização do candomblé numa época de tanta intolerância religiosa em relação às crenças de origem africana e afro-brasileiras.

\section{O CANDOMBLÉ E SUA RIQUEZA SIMBÓLICO-CULTURAL}

Começamos esta parte de nosso artigo buscando entender um pouco sobre o candomblé e como esta religião se configurou em solo brasileiro. Reginaldo Prandi relata-nos sobre o período colonial de tráfico negreiro para o Brasil e sobre a multiplicidade de povos negros que para cá foram traficados:

Entre os anos de 1525 e 1851, mais de cinco milhões de africanos foram trazidos para o Brasil na condição de escravos, não estando incluídos neste número, que é uma aproximação, aqueles que morreram ainda em solo africano, vitimados pela violência da caça escravista, nem os que pereceram na travessia oceânica. Não se sabe quantos foram trazidos desde que o tráfico se tornou ilegal. Ao longo de mais de três séculos, enquanto a própria nação brasileira se formava e tomava corpo, os africanos foram trazidos das mais diferentes partes do continente africano abaixo do Saara (...). Não se tratava de um povo, mas de uma multiplicidade de etnias, nações, línguas, culturas. No Brasil foram sendo introduzidos nas diferentes capitanias e províncias, num fluxo que corresponde ponto por ponto à própria história da economia brasileira. (PRANDI, 2000, p. 52)

Também, o professor José Pacheco de Oliveira fala-nos da importância da mão de obra escravizada dos negros para a construção econômica do Brasil, assim como da relevância da mão de obra indígena. Tratados como mercadorias que podiam ser compradas e vendidas, os negros, vindos das mais distintas regiões da costa da África, foram forçados a trabalhar nas plantações de cana-de-açúcar e serem vendedores nas cidades (escravos de ganho): 
[...] o tráfico de escravos africanos, que gerava trabalhadores classificados e transacionados como mercadoria, sem passar portanto pelas regras limitativas que eram aplicadas aos indígenas ("negros da terra"). À medida que a produção do açúcar se expandia, a utilização de escravos africanos passou a ser a opção básica dos plantadores de cana, enquanto o trabalho indígena, a partir do século XVII, era destinado a atividades complementares (como a produção de alimentos, os trabalhos pesados e mais arriscados). (OLIVEIRA, 2010, p. 27)

Durante muito tempo afirmou-se que os negros que no Brasil chegaram não trouxeram nada consigo. Contudo, sabemos que eles podem até terem vindo despidos materialmente de sua cultura, mas vieram vestidos de rica memória histórica e cultural. Prandi revela-nos a fortíssima carga cultural trazida pelos negros escravizados vindos da África e que aqui aportaram. A multiplicidade de etnias forçadas a virem para o Brasil ainda pode ser identificada em nossa sociedade atual.

Em anos recentes, estudos linguísticos demonstraram a sobrevivência no Brasil de elementos originários principalmente do quicongo, quimbundo e umbundo, o que nos dá uma boa pista da superioridade demográfica, entre os bantos no Brasil, dos africanos provenientes do Congo e de Angola, onde estas línguas são faladas. De fato, reminiscências culturais desses grupos são conhecidas entre nós como congo, angola e cabinda, hoje usando-se genericamente o termo angola para todos os bantos, sobretudo quando se trata da designação de religião afro-brasileira de origem banto ou de outra modalidade cultural, como a capoeira, luta marcial afro-brasileira. (PRANDI, 2000, p. 54, grifo nosso)

Assim percebemos que muitas das tradições, línguas, religiosidades, hábitos alimentares etc de diversas civilizações africanas que tiveram seus povos escravizados foram trazidas para o Brasil. Chegaram africanos das mais diversas origens étnicas. Boa parte da cultura destes povos somente sobreviveu em terras brasileiras porque foram afirmadas pela religião dos Orixás, o candomblé, através de seus rituais e seus conhecimentos. E isto aconteceu não somente no Brasil, mas em grande parte da América Latina, como nos informa Prandi:

[...] as nações, como tradições culturais, foram preservadas na forma de candomblé no Brasil, santeria em Cuba e vodus no Haiti, cada grupo religioso compreendendo variantes rituais autodesignadas pelos nomes de antigas etnias africanas. Assim, na Bahia, temos os candomblés nagôs ou iorubás (ketu ou queto, ijexá e efã), os bantos (angola, congo e cabinda), os ewe-fons (jejes ou jejes-mahis). Em Pernambuco, os xangôs de nação nagô-egbá e os de nação angola. No Maranhão, o tambor-de-mina das nações mina-jeje e mina-nagô. No Rio Grande do Sul o batuque oió-ijexá, também chamado de batuque de nação. (PRANDI, 2000, p. 58, grifo nosso)

Vale ressaltar que nossa compreensão do que seria a religião do candomblé brasileiro alinha-se com a concepção de Reginaldo Prandi, onde candomblé é designado como: tradições de povos iorubás, ou nagôs, com influências de costumes 
trazidos por grupos fons, aqui denominados jejes, e residualmente por grupos africanos minoritários. O candomblé iorubá, ou jeje-nagô, como costuma ser designado, congregou, desde o início, aspectos culturais originários de diferentes cidades iorubanas, originando-se aqui diferentes ritos, ou nações de candomblé, predominando em cada nação tradições da cidades ou região que acabou the emprestando o nome: queto, ijexá, efã. (PRANDI, 2001, p. 44)

Prandi destaca, ainda, que a religião do candomblé como a conhecemos hoje em dia é uma construção de várias tendências religiosas africanas, tendo sido aglomeradas no século XIX, e que seria quase que impossível traçar uma linha histórica precisa em relação à fundação dos terreiros de candomblé, isto porque muitos terreiros foram mantidos por décadas em sigilo devido a perseguição da Igreja e da polícia, e porque os escravos negros africanos trabalhavam com uma concepção de tempo diferente daquela dos colonizadores:

Embora o candomblé e outras religiões de origem africana sejam de formação recente, aqui constituídas somente depois das primeiras décadas do século XIX, as datas de fundação dos terreiros, assim como as que marcam os reinados de sucessivas mães e pais-de-santo no início, são desconhecidas. Seus nomes são bem lembrados e seus feitos são cantados e festejados nas cerimônias que louvam os antigos fundadores - o padê nos candomblés mais velhos -, mas nada de datas. Esse passado brasileiro também já se fez mito. (PRANDI, 2001, p. 48)

Vale ressaltar que o candomblé é uma religião com forte estrutura simbólica, ligada a elementos naturais e sobrenaturais e cheia de signos sendo alguns destes signos somente conhecidos pelos iniciados mais antigos:

[...] a estrutura organizacional do candomblé é uma reprodução simbólica da estrutura tradicional da família iorubá, de resto perdida no Brasil, evidencia-se a importância da experiência acumulada na constituição dos grupos de autoridade. Os ebômis são os que sabem, porque são mais velhos, viveram mais, acumularam maior experiência. Sua autoridade é dada pelo tempo acumulado, que pressupõe saber maior. (PRANDI, 2001, p. 54)

No Brasil, atualmente, na religião do candomblé cultuam-se, principalmente, 16 orixás (para alguns eles são compreendidos como deuses, para outros como forças/energias da natureza, ou ainda como ancestrais divinizados), considerando também os chamados Ibejis, ou orixás infantis. Cada orixá tem sua própria simbologia, caraterísticas, dias da semana, ocupações, cores, elementos naturais, rezas, saudações, comidas e, até mesmo, horários, entre outras especificidades. Acredita-se que haja um número superior a 400 entidades desta religião de matriz africana, sendo algumas cultuadas somente por determinadas tribos africanas praticantes de religião semelhante.

Cada Orixá tem forte relação com determinado elemento da natureza, e a força de seu elemento natural caracteriza suas personificações. Eles aproximamse muito dos humanos em relação aos sentimentos, podendo ter raiva, amor, inveja, paixão etc, e dos desejos carnais como apreço por comidas, bebidas e sexo. Isso faz com que estas entidades espirituais se pareçam e estejam mais próximas do cotidiano e experiência de seus devotos. Cada Orixá possui um ou mais objetos 
que os caracterizam e que revelam suas atividades mitológicas e espirituais Vamos a algumas informações sobre alguns dos Orixás mais cultuados no Brasil (vale lembrar que aqui somente colocamos algumas informações básicas sobre alguns dos Orixás mais cultuados no Brasil, isto com o intuito de clarificar as explicações sobre as obras de Valentim):

EXU - por ser o orixá dos caminhos e o mensageiro dos Orixás, todos os rituais do candomblé iniciam-se prestando reverência a ele. A segunda-feira é seu dia de celebração. Suas cores são o preto (representando seu conhecimento) e o vermelho (representando sua coragem). O símbolo de Exu é o ogó, objeto de aparência fálica que representa a relação de Exu com a sexualidade e fertilidade.

OBALUAIÊ - Orixá também das segundas-feiras, sendo o Orixá da medicina, da cura e das doenças. É ele quem olha pelos doentes e enfermados. Suas cores são o preto e o branco. Seu símbolo é um xaxará (uma espécie de cetro).

OGUM - Orixá das terças-feiras. É um Orixá guerreiro, forjador dos metais e senhor das guerras. Ele simboliza a luta pela vida e as forças espirituais e físicas. Suas cores são o verde e o azul-escuro. Seus símbolos principais são uma espada e um escudo, mas é comum outras ferramentas que representem as guerras e as lutas e a metalurgia.

OXUMARÊ - É o Orixá da fortuna e da riqueza, representado também como o ciclo da vida. Seu dia é a terça-feira. Suas cores são aquelas do arco-íris. Seu símbolo é o Ebiri (espécie de vassoura feita com nervuras das folhas das palmeiras) e a serpente.

IROKO - É um Orixá do candomblé Keto. Representa o tempo e é celebrado na terça-feira. Seu símbolo é uma árvore conhecida como gameleira.

IANSÃ - Orixá feminino e que se associa à força natural dos ventos, das tempestades e dos raios. Seu dia é a quarta-feira. Suas cores são: marrom, vermelho e rosa. Seus símbolos são uma espada e um Eruexin, uma espécie de chicote feito a partir do rabo do búfalo ou cavalo.

XANGÔ - Orixá guerreiro, corajoso e muito popular do candomblé no Brasil, pois personifica a justiça e tudo ligado a ela. Suas cores são o vermelho e o branco. Seu símbolo é o Oxé, um machado de dois gumes.

OBÁ - Orixá feminino ligado ao poder dos ventos, sendo a senhora dos redemoinhos e das águas revoltosas. Seu dia da semana é a quarta-feira. Foi esposa de Xangô e compartilha com ele as cores vermelho e branco. Por ser guerreira ela usa espada, escudo, e um Ofá (arco e flecha).

OXÓSSI - Seu dia da semana é a quinta-feira. É o Orixá das matas, da fartura, do sustento, da caça e de todos os seres que habitam as matas. Sua cor é o azulturquesa ou o verde, e o seus símbolos são o Ofá (um arco) e o Damatá (uma flecha).

LOGUN EDÉ - Também é um Orixá caçador, conhecido como o senhor da pesca e da caça. Seu dia é a quinta-feira. Seus símbolos são o Ofá, a lança de caça, facão e o ogue (instrumento musical semelhante a um berrante).

OSSAIM - Seu dia é a quinta-feira. Ele detêm os segredos das plantas das matas, essenciais para os rituais e banhos do candomblé, assim como para remédios e venenos. Seus objetos simbólicos são um pilão e o Opassanìn, um 
instrumento de sete pontas, com a do centro levando em sua ponta um pássaro no alto.

OXALÁ - É o Orixá mais conhecido do candomblé. Seu dia é a sexta-feira e somente ele tem este dia. Seu nome Oxalá é usado como expressão diária equivalente a "queira Deus". Sua cor é o branco e o seu símbolo é o Opáxoró, um cajado metálico. O Opáxoró liga-se à criação do mundo, do homem e à sapiência dos mais velhos. Ele serve de apoio para a locomoção de Oxalá, considerado o pai da criação. O Opáxoró simboliza, também, a ligação entre o céu (Orun) e a terra (Ayê) e os planetas.

OXUM - Orixá feminina, ligado à maternidade, à fraternidade, ao amor e às águas dos rios e cachoeiras. Sua cor é o amarelo-ouro e o seu símbolo é o Abebé ${ }^{\text {, }}$ um leque circular com espelho, assim aquele do Orixá lemanjá. Seu dia é o sábado.

IEMANJÁ - Orixá feminina, dos mares, mãe de todos e espelho do mundo. Seu dia da semana é o sábado, junto com Oxum. Foi a segunda esposa de Oxalá. As cores desta Orixá são o branco, o prateado, o azul e o rosa. O seu símbolo é o Abebé prateado.

NANÃ - Orixá feminino dos mais antigos do candomblé. Está associado aos idosos, aos mistérios, à maternidade, às águas profundas e lamacentas, e aos castigos educativos. Seu dia é a terça-feira. Sua cor é o violeta. Seu símbolo é o Ibiri, um bastão de hastes de palmeira. Esse bastão tem a finalidade de afastar a morte.

IBEJI (ERÊS) - Seu dia é o domingo. São Orixás crianças gêmeas e estão ligadas aos doces e brinquedos infantis. Seu símbolo é a representação de duas cabaças.

Vale informar que esses são somente alguns dos Orixás cultuados no candomblé do Brasil, havendo muitos outros Orixás africanos que não são nem conhecidos nos cultos afro-brasileiros e tampouco venerados por aqui. Ainda, a riqueza mitológica dos Orixás é riquíssima, chegando até nós por tradição oral mantida pelos africanos escravizados e seus descendentes.

Também, é importante informar que há várias grafias para os nomes dos Orixás. Do mesmo modo, cada orixá pode receber um nome diferente ou uma espécie de sobrenome quando se trata de momento específico de sua vida (criança, jovem, adulto, velho) ou de onde sua energia impera naquele momento nos elementos da natureza. Os Orixás estão conectados às energias dos elementos fogo, ar, terra e água. Sendo assim, dentre os orixás que apresentamos temos a seguinte relação: Nanã, lemanjá e Oxum: água; Oxóssi, Ossaim e Obaluaiê: terra; Oxalá e lansã: ar; Xangô e Ogum: fogo. É certo que alguns orixás podem compartilhar mais que um elemento dependendo da sua atuação, como é o caso de Logun Edé que transita entre água e terra, ou lansã que transita entre ar e terra.

\section{O CASO DAS OBRAS VISUAIS DE RUBEM VALENTIM}

O filósofo Paulo Ghiraldelli Júnior (2010) aponta-nos a direção da arte enquanto forma de linguagem. A linguagem das artes pode nos enriquecer com seus textos sensoriais e sensíveis, provocando acontecimentos que produzam respostas e devires complexos na subjetividade individual e coletiva: 
A obra de arte é tomada como linguagem, e isso não é em sentido metafórico. É observada e estudada a partir de categorias como significação, referência, denotação, regras sintáticas e semânticas etc. A arte é observada como um sistema de símbolos. Nelson Goodman a levou para o campo da "estética analítica", e os estudos que, em geral, são feitos a respeito da linguagem no século XX, voltaram-se para a obra de arte, da música à literatura, passando por todo o campo das artes visuais. (GHIRALDELLI JR., 2010, p. 87)

E é nesta seara da arte, enquanto forma de linguagem, que trabalhamos neste texto, pois os trabalhos artísticos de Rubem Valentim tomam para si as categorias simbólicas do candomblé para criar uma forma de arte única, revelando-nos signos novos em sua composição de imagens e cores com forte conotação afro-brasileira.

Rubem Valentim (Salvador, 1922 - São Paulo, 1991) foi um conhecido pintor, gravador, escultor e professor brasileiro, tendo sido um dos pilares do movimento artístico brasileiro conhecido como construtivismo. No catálogo online da Paulo Darzé Galeria temos as seguintes informações sobre este artista:

Nasceu num sobrado com sacadas de ferro, à Rua Maciel de Baixo, 17, Distrito da Sé em 1922. De pais pobres, foi o primeiro dos seis filhos. Formou-se em Odontologia, área que abandonou para dedicar-se à pintura em 1948. Em 1957 transferiu-se para o Rio de Janeiro. Em 1962 conquistou o Prêmio de Viagem à Europa no Salão Nacional de Arte Moderna e Pequena Medalha de Ouro no Salão Paulista de Arte Moderna. Viaja para a Europa: Inglaterra, França, Holanda, Bélgica, Alemanha, Áustria, Espanha, Portugal e Itália. Residiu em Roma de 1964 a 1966, quando voltou para o Brasil. Participou da Bienal de Veneza e diversas vezes da Bienal de São Paulo (de 1955 a 1998, Prêmio de Aquisição em 1967 e 1973, Sala Especial em 1998). Em 1994, o Centro Cultural Banco do Brasil, no Rio de Janeiro, montou uma grande retrospectiva de sua obra. Em longo texto que escreveu para o catálogo/livro dessa exposição, Frederico Morais aponta com lucidez o caráter inovador da obra de Rubem Valentim. Recentemente, sua obra foi objeto de salas especiais (1996, Bienal de São Paulo; 1998, Parque de Esculturas do Museu de Arte Moderna da Bahia) e de duas novas retrospectivas: Pinacoteca do Estado de São Paulo (2001) e Museu Nacional de Belas Artes, Rio de Janeiro (2002). Faleceu no dia 30 de novembro de 1991 em São Paulo SP. (PAULO DARZÉ, s/a, s/p)

O construtivismo pode ser entendido como um movimento estético começado na Rússia, em 1917 (ano da Revolução Russa), com o pintor Kazimir Malevich (1879-1935). O construtivismo é filho da Primeira Guerra Mundial (19141918), daí a ideia de que a arte detinha sua própria forma de criação, algo inovador. Tal movimento foi movido pelas esperanças criadas a partir do socialismo russo (marxismo e Revolução Russa) e buscava uma "modernidade" compositiva das obras. A utopia, a tecnologia e o vanguardismo dos artistas eram a voga no concretismo. O movimento durou até 1934 , quando deu lugar ao realismo de cunho social russo. As composições construtivistas privilegiavam as formas geométricas na feitura das obras, utilizavam muito as cores primárias e a fotomontagem, privilegiando uma arte não-figurativa. O construtivismo russo almejava a socialização da arte, não sua politização, como acabou acontecendo com o realismo social russo. 
No Brasil, o construtivismo reatualizado de Rubem Valentim (nas décadas de 1950 e 60) utilizava-se de formas geométricas ligadas a elementos dos cultos afrobrasileiros, como o candomblé ${ }^{2}$. Uma das imagens mais utilizada por Valentim era a do Oxê de Xangô, o machado duplo que este Orixá traz para suas lutas. Podemos dizer que Valentim reelabora a estética construtivista à sua maneira, compondo suas obras a partir da utilização dos signos dos Orixás e inspirando-se fortemente nas ferramentas e nos elementos simbólicos e pictóricos do candomblé.

Também podemos verificar que ele cria uma linguagem própria a partir dos elementos e ferramentas dos Orixás do candomblé, ressignificando estes objetos para a arte abstrata. Neste sentido, sua arte toma uma clara forma de linguagem visual individual, revelando suas influências afro-brasileiras em suas releituras dos elementos do candomblé. Se encaramos sua arte como uma forma de linguagem, podemos tentar ler suas obras como textos visuais.

O professor Roberto Conduru expande o conceito de arte afro-brasileira para todos os artistas que trabalham com os temas da negritude no Brasil (diretamente ou por vias simbólicas). Sobre a obra de Rubem Valentim, Conduru vê as mais variadas influências construtivistas, mas também a relevância da temática afrodescendente:

[...] a arte afro-brasileira não tem sido identificada exclusivamente pela temática afro-descendente. Pois também há quem a caracterize sem circunscrevê-la a temas africanos e afro-descendentes no Brasil, embora os tenha como os núcleos principais de sua definição. É o que se pode ver na obra de Rubem Valentim. (CONDURU, 2009, p. 32)

O próprio Rubem Valentim definia sua linguagem artístico-expressiva com um forte peso cultural baiano, onde a religiosidade tem grande força simbólica, mágica e visual. Ele nos diz que:

Minha linguagem plástico-visual-signográfica está ligada aos valores míticos profundos de uma cultura afro-brasileira (mestiça-animistafetichista). Com o peso da Bahia sobre mim - a cultura vivenciada; com o sangue negro nas veias - $\mathrm{o}$ atavismo; com os olhos abertos para o que se faz no mundo - a contemporaneidade; criando seus signossímbolos procuro transformar em linguagem visual o mundo encantado, mágico, provavelmente místico que flui continuamente dentro de mim. (VALENTIM apud CONDURU, 2009, p. 32)

O professor Roberto Conduru expande a compreensão da arte afro-brasileira como uma arte não executada somente por artistas negros, mas busca entender as nuances culturais africanas nas várias modalidades artísticas no Brasil. Ressaltamos que muitos dos artistas que produzem artes afro-brasileiras na atualidade e tem reconhecimento de seu trabalho em âmbito cultural e social não são negros. Antes de significar a ausência de artistas negros, tal afirmação diz mais sobre o racismo estrutural que temos no Brasil, ou seja, artistas negros que falam, cantam, pintam, esculpem e declamam a cultura afro-brasileira tem aos montes, 0 que não se tem é a mesma oportunidade e visibilidade que os brancos conseguem nos meios de divulgação, sejam eles qual for. Neste caminho, é importante destacar neste artigo o artista Rubem Valentim e sua arte afro-brasileira a fim de 
proporcionar mais visibilidade no meio acadêmico da população negra e de seus trabalhos.

Rubem Valentim incorporando os signos e elementos do candomblé em sua arte, trabalha com toda as noções e significações específicas desta religião dos Orixás, dando às suas obras um caráter mítico, quase que secreto para aqueles não iniciados na religião. Prandi fala-nos das especificidades significativas do candomblé e que podem parecer estranhas ao olhar ocidental. Para o autor, "As noções de tempo, saber, aprendizagem e autoridade, que são as bases do poder sacerdotal no candomblé, de caráter iniciático, podem ser lidas em uma mesma chave" (PRANDI, 2001, p. 44) diferente do encontrado nas Américas, cultura predominantemente ocidental, onde tempo e saber têm outros significados. É certo que Prandi aqui ressalta o caráter ocidental pós colonização, não levando em consideração a proximidade existente entre as noções africanas e indígenas.

Desta maneira, vale buscar compreender (ler) uma das obras deste artista brasileiro. Tomamos aqui a obra de Rubem Valentin, uma serigrafia (ver figura 1), sem título, de 1989. Tentaremos fazer uma leitura da textualidade visual da obra. Apesar de a obra não ser do período inicial do construtivismo de Valentim, ela nos dá um claro exemplo de sua linguagem estética.

FIGURA 1 - Rubem Valentim. Serigrafia sem título, de 1989.

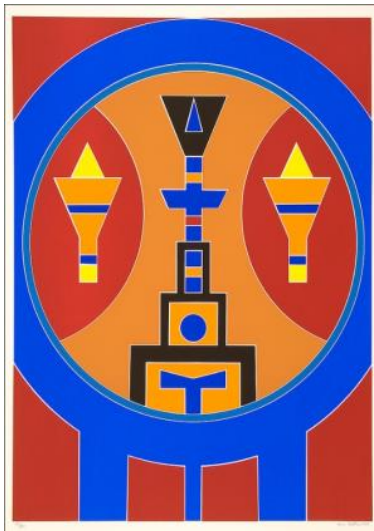

Fonte: Museu Afro Brasil ${ }^{3}$

A referida obra de Rubem Valentim chama nossa atenção pelo intenso uso das cores primárias. Ao centro de um círculo podemos ver o que poderia ser um opáxoró de Oxalá ou mesmo uma cruz cristã sobre uma espécie de altar representando Jesus Cristo com quem Oxalá é sincretizado. Na base deste opáxoró podemos perceber um oxé de Xangô estilizado. Como Xangô foi um grande defensor de Oxalá, acreditamos que estes objetos em cena façam referência a relação de amizade entre estes dois orixás. $O$ fato do oxé estar na base da imagem ainda pode indicar que a sustentação das religiões deve se encontrar na justiça, e por que não dizer em uma justiça por igualdade entre todos os credos? Nas laterais acreditamos haver dois objetos ligados ao fogo, como tochas. Vemos que o opáxoró está dentro de uma forma circular, o que poderia representar um abebé de lemanjá ou de Oxum. Vale ressaltar que a circularidade ainda representa um continuum na relação estabelecida entre vivos e mortos, entre este mundo (Ayê) e o outro (Orun), entre a humanidade e os orixás.

Como vemos, todos os elementos compositivos da obra analisada revelam formas geométricas e cores primárias, com adição do preto. Não há como dar um 
significado único para este trabalho, mas explorar seus arranjos de imagens e signos. A obra parece nos atrair por suas cores e nos instigar a buscar interpretação para seus arranjos geométricos. Além disto, a obra demonstra grande equilíbrio, pois as formas parecem espelhar-se. A centralidade do objeto central fornece firmeza e direcionamento à obra, levando-nos para cima.

FIGURA 2 - Rubem Valentim. Pintura a óleo sobre madeira, de 1977.

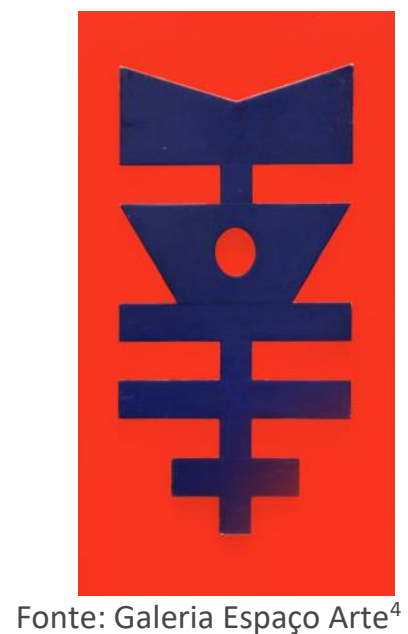

Escolhemos uma segunda obra (figura 2) para ser analisada, esta intitulada "Emblema", é uma pintura a óleo sobre madeira, de 1977, com dimensões 63 × 42 $\mathrm{cm}$. Este trabalho de Valentim mostra claramente um Oxé, machado de dois gumes, de Xangô, em azul e sobre fundo vermelho. O vermelho é uma das cores do Orixá Xangô e a escolha por duas cores primárias faz com que a imagem grite a nossos olhos. A base do Oxé traz formas geométricas que dão mais firmeza estrutural à imagem.

Tal técnica de pintura a óleo sobre madeira foi somente uma das muitas técnicas artísticas utilizadas por Rubem Valentim, pois ele também foi um profícuo gravurista, nas mais diversas formas de gravura e um escultor muito procurado, pois suas obras, além de mostrarem importantes facetas da sociedade negra brasileira, eram pensadas a partir de uma base construtivista e com materiais bastante duráveis, como o concreto para o exterior dos ambientes e a madeira para os interiores, além da grande qualidade estética de seus trabalhos. Vide a obra "Marco Sincrético da Cultura Afro-Brasileira" ${ }^{5}$, uma escultura de concreto colocada fora da estação de metrô Praça da Sé de São Paulo.

Vemos o trabalho efetivo de construção de formas abstratas e harmoniosas, buscando instigar pensamentos e emoções através de uma linguagem simbólica própria, deixando perceber a maneira única de criação de Rubem Valentim. Esta ideia em partir dos elementos do candomblé, suas formas e seus signos e incorporar estes elementos a uma maneira construtivista de composição dos seus trabalhos fez com que Valentim inventasse uma estética própria e individual, algo muito difícil para um artista da atualidade. Tal inventividade deu as suas obras um ar enigmático e misterioso, numa linguagem difícil de ser decifrada, mas agradável de ser experienciada. 


\section{CONSIDERAÇÕES FINAIS}

Este texto buscou compreender a utilização efetiva da simbologia dos orixás do candomblé nas artes plásticas brasileiras, principalmente na obra de Rubem Valentim. Tentamos mostrar um pouco da história dos negros escravizados e trazidos para o Brasil e que foram explorados nos trabalhos pesados da agricultura e do ganho citadino. Tais escravos foram os responsáveis por nos trazer os Orixás africanos e aqui construir uma religião que os agregasse. Verificamos como o candomblé funciona e como seus Orixás detêm uma imensa força simbólica na mitologia, nos rituais e na estrutura desta religião, que no Brasil se tornou mais plural e diversificada. Do mesmo modo, vimos como os orixás são representados no mundo externo aos terreiros e como ganham uma brasilidade através de artistas como Rubem Valentim.

Vimos que indivíduos das mais várias etnias africanas, que para o Brasil foram traficados, contribuíram para a formação de um candomblé digamos "brasileiro", diferente daquele culto religioso de Cuba, do Haiti, e de outros países da América Latina. Vale ressaltar nossa compreensão do candomblé como sendo uma religião de acolhimento da humanidade das pessoas, podendo auxiliar na sua maior aceitação, pois revela características dos Orixás muito próximas daquelas dos humanos. Isto mostra-se relevante num momento de tanta intolerância religiosa em que atravessamos e onde somente são valorizadas as religiões cristãs.

A arte de Rubem Valentim pode auxiliar-nos a acabar com os estereótipos negativos em relação aos Orixás, ao candomblé e a seus rituais, deixando ver a riqueza simbólica desta religião e as fortes ligações dos Orixás com os elementos naturais e da natureza humana. Do mesmo modo, falar da arte de Rubem Valentim é um modo de proporcionar visibilidade ao seu trabalho enquanto artista negro que busca difundir a cultura afro-brasileira, e instigar novos pesquisadores a conhecerem seu trabalho.

Vemos que as obras de artes visuais de Rubem Valentim engendram-se em um jogo representacional dos mais avançados processos artísticos de sua época, gerando novas possibilidades para o exercício da criatividade estética. Seus trabalhos produzem novas formas e novos sentidos para o construtivismo brasileiro a partir da simbologia afro-brasileira obtida no candomblé, construindo plataformas de conhecimentos e pensamentos intensificados.

Concluindo, compreendemos que Valentim reinventou no quotidiano das artes plásticas de sua época formas inovadoras e ousadas para a representação dos símbolos dos orixás do candomblé, entrelaçando fortes referências religiosas, aspectos culturais, formas minuciosamente escolhidas e cores específicas, fazendo com que seus arranjos artísticos fossem mais potentes simbolicamente do que uma mera soma de formas abstratas. 


\title{
The symbolic richness of candomblé in Brazilian visual arts: the case of Rubem Valentim
}

\begin{abstract}
This paper seeks to think about the symbolic and cultural wealth that enslaved blacks brought from Africa to Brazil and which resists and takes strength in the Candomble religion. A multiplicity of black African peoples was forced to come to Brazil and such peoples can still be identified in our current society. Influencing the most diverse Brazilian cultural areas, the black population contributed significantly to the constitution of what is now Brazil. Enslaved blacks from different places on the African continent brought with them a strong historical and cultural memory. They also brought their religious beliefs and their orixás. In this text, we will take as a study case the art of Bahian visual artist Rubem Valentim (Salvador, 1922 - São Paulo, 1991), an important user of candomblé signs to compose his visual works of abstract art. Valentim created an unique and true aesthetic language with the use of candomble signs in his work. This research has an analytical-qualitative nature and it seeks its bases in a bibliography in the areas of anthropology and the arts. The results of this work show the fundamental relevance of Candomble in the Brazilian cultural formation and its insertion in the most varied areas of knowledge and practices, just as it did in the plastic arts and, especially in the works of Rubem Valentim, who was extremely influenced by Candomblé. In addition, this text can assist in the dissemination of abstract Afro-Brazilian art, making known not only the visual art of the artist Rubem Valentim, but instigating other searches in relation to the arts and candomblé.
\end{abstract}

KEYWORDS: Candomblé. Symbols. Rubem Valentim. Visual arts. 


\section{NOTAS}

${ }^{1}$ O Abebé de Oxum é dourado e pode ter desenhos simbólicos de corações e o de lemanjá é prateado e pode ter desenhos de peixes.

${ }^{2}$ Vale ressaltar que outros artistas brasileiros e estrangeiros também foram inspirados pelos cultos afro-brasileiros, como Hector Carybé, Pierre Verger, Mestre Didi, Wilson Tibério, entre muitos outros.

${ }^{3}$ Disponível em: http://www.museuafrobrasil.org.br/images/defaultsource/rubem-valentim/rubem-valentim-serigrafia-sem-titulo1989 mab2199.jpg?sfvrsn=2.

${ }^{4}$ Disponível em: https://www.espacoarte.com.br/obras/5140-emblema.

${ }^{5}$ Disponível em: https://artenalinha.files.wordpress.com/2014/04/obra-derubem-valentim- 4 -praca-da-se- -credito-nario-barbosa.jpg.

\section{REFERÊNCIAS}

CONDURU, R. Negrume Multicor. Arte, África e Brasil para além de raça e etnia. Acervo. Rio de Janeiro, v. 22, no 2, p. 29-44, jul/dez 2009.

GHIRALDELLI JÚNIOR, P. História essencial da Filosofia. São Paulo: Universo dos Livros, 2010.

OLIVEIRA, J. P. de. O Nascimento do Brasil: Revisão de um paradigma historiográfico. Anuário Antropológico. Museu Nacional, UFRJ, p. 11-40, 2009-1, 2010.

PAULO D., Galeria de Arte. Rubem Valentim. Salvador. Sem ano. Disponível em: https://paulodarzegaleria.com.br/artistas/rubem-valentim/. Acesso em 16 jul. 2020.

PRANDI, R. De africano a afro-brasileiro: etnia, identidade, religião. Revista USP. São Paulo, n.46, p. 52-65, junho/agosto 2000.

O candomblé e o tempo. Concepções de tempo, saber e autoridade 
VALENTIM, R. Manifesto ainda que tardio. 1976. IN: CONDURU, Roberto. Negrume Multicor. Arte, África e Brasil para além de raça e etnia. Acervo. Rio de Janeiro, v. 22, no 2, p. 29-44, jul/dez 2009.

Recebido: 29 jul. 2020

Aprovado: 20 set. 2020

DOI: $10.3895 /$ rl.v22n38.12876

Como citar: RODRIGUES, Walace; VENÂNCIO, Sariza Oliveira Caetano. A riqueza simbólica do Candomblé nas artes visuais brasileiras: o caso de Rubem Valentim. R. Letras, Curitiba, v. 22, n. 38 p. 01-14, set. 2020. Disponível em: <https://periodicos.utfpr.edu.br/rl>. Acesso em: XXX.

Direito autoral: Este artigo está licenciado sob os termos da Licença Creative Commons-Atribuição 4.0 Internacional. 